Federal Reserve Bank of Minneapolis

Research Department Staff Report 207

February 1996

\title{
How Prescribed Policy Can Mislead When Data Are Defective: A Follow-up to Srinivasan (1994) Using General Equilibrium
}

\author{
Jean Mercenier* \\ C.R.D.E. and Département de sciences économiques, Université de Montréal \\ Erinç Yeldan* \\ Department of Economics, Bilkent University
}

\begin{abstract}
We highlight an example of considerable bias in officially published input-output data (factor-income shares) by an LDC (Turkey), which many researchers use without question. We make use of an intertemporal general equilibrium model of trade and production to evaluate the dynamic gains for Turkey from currently debated trade policy options and compare the predictions using conservatively adjusted, rather than official, data on factor shares. We show that the predicted welfare gains are not only of a different order of magnitude, but in some cases, of a different sign, hence, suggesting contradictory policy recommendations.
\end{abstract}

"The paper was partly written while Mercenier was visiting the Research Department of the Federal Reserve Bank of Minneapolis and Yeldan was visiting the Applied Economics Department of the University of Minnesota. We thank these institutions and our colleagues there for their hospitality. We in particular wish to thank (without implicating) Tim Kehoe and Terry Roe for helpful discussions. We are also grateful to Merih Celasun for encouragements. Mercenier gratefully acknowledges financial support from the FCAR of the Government of Quebec and the SSHRC of the Government of Canada. The views expressed herein are those of the authors and not necessarily those of the Federal Reserve Bank of Minneapolis or the Federal Reserve System. 


\section{Introduction}

The concern that analyses based on unreliable and biased data can result in seriously distorted, if not altogether wrong, development policy recommendations led to the recent publication, under the leadership of T.N. Srinivasan, of a special issue of the Journal of Development Economics. The symposium, entitled "Data Base for Development Analysis," has two stated aims: to take stock of the situation regarding reliability of available data and to provide a feasible recommendation for improvement. The primary recommendation of the group of experts is, in Srinivasan's words, that "greater resources have to be provided internationally and nationally for improving data gathering and analytical capability of most developing countries. Policy analysis with the existing data base is fraught with potentially serious pitfalls" (Srinivasan 1994a, p.2).

Perhaps what is lacking in the aforementioned special issue is a spectacular and provocative example of how even the most basic officially reported data can be (presumably more often than not) unquestionably erroneous, and how such flaws can make any quantitative analysis meaningless because they can lead to misguided policy conclusions. Such an example can only have forcefully complemented recommendations "that are stated in a somewhat provocative language to stimulate discussion and possibly some corrective action" (Srinivasan 1994b, p.24).

It is our aim in this paper to provide one such example. More specifically, we highlight the fact that, according to the officially published Turkish input-output (I-O) data, the Turkish economy is highly capital-intensive with capital shares in value added close to 80 percent in most sectors. Such numbers are unquestionably inconsistent with current economic theory and suggest substantial measurement errors. We then use an intertemporal general equilibrium (GE) model of trade and production to evaluate the dynamic gains for Turkey from alternative trade policies and compare the model's predictions under conservatively adjusted, rather than official, data on factor shares. We report predicted welfare gains not only of a different order of magnitude, but in some cases, of a different sign, hence, suggesting contradictory policy recommendations.

Spectacular as it is, there is nothing pathological about this example. It is actually interesting in many different respects:

(a) Though possibly not as good as India's, Turkey's statistical system of data collection, processing, and analysis is fairly well developed, certainly more so than systems in most lessdeveloped countries (LDCs). In terms of reliability, one can therefore expect Turkish official data to be above LDC averages. 
(b) Similar data have been used by many different authors (among others, Senses 1990, Ozmucur 1991, Bulutay 1993, Harrison et al. 19931', Boratav et al. 1994, Temel 1993, Yeldan $1995)$ without any mention of the data problem. ${ }^{2}$

(c) A large overstatement of the capital share in value added is not uncommon in LDC official statistics. Kehoe and Kehoe 1994 (p.18) have recently called attention to the fact that official Mexican sources report labor as generating only 30 percent of total factor income in Mexico. According to their investigation, many of the most influential applied GE assessments of the potential impact of the North American Free Trade Agreement (NAFTA) use these numbers without question. It is therefore hardly surprising that liberalizing capital flows has been predicted to generate large welfare gains for Mexico. In view of the unreasonably capitalintensive nature of the Mexican technology utilized for making these predictions, one should be suspicious of the likelihood that these welfare gains can be realized. Thus, Srinivasan's accusing comments that "[u]nfortunately, it would appear that researchers either are not aware of or, worse still, have chosen to ignore the fact that the published data, national and international, suffer from serious conceptual problems, measurement biases and errors" (Srinivasan 1994b, p.4) should not be taken as an overstatement and should be paid due attention.

(d) The example also highlights the potential danger of excessive (or naive) standardization in data processing and definitions. It appears ${ }^{3}$ that the most likely explanation for the unreasonably high share of capital income in Mexico is that, following U.S. practice, the earnings of selfemployed labor are treated as capital rents. Though this may make sense in the United States where such remuneration is relatively small, it is obviously much more questionable in the Mexican context where the figure is quite large.

(e) The importance of systematic sensitivity analysis with respect to key exogenously supplied parameter values is emphasized in the applied GE literature. Some researchers (e.g., Harrison et al. 1993) put a lot of effort into such exercises and should be praised for it. This example shows,

1 We thank Glenn Harrison for kindly making available to us the data base used for the Harrison et al. 1993 paper.

2 A notable exception is Celasun 1989, who identifies the problem and restricts his analysis accordingly. He warns about "the limited share of wage labor in total employment in interpreting the estimated factor shares in national income" (Celasun 1989, p.9). He argues that the historical series for the labor market have been altered each time a new five-year development plan is drafted and that about 70 percent of total employment remains in the nonwage status, mainly in agriculture. Under such data limitations, he goes on to limit his analysis on "broad structural features and major proportional shifts over time" (Celasun 1989, p.5).

3 According to T. Kehoe, personal communication. 
however, that a critical assessment of the data set may be equally important as "any AGE [applied GE] model is only as good as the data used to calibrate it" (Kehoe and Kehoe 1994, p.18).

(f) Last but not least - and worth stressing — we do not invoke any dubiously extreme assumption nor resort to questionable country characteristics in designing the model structure and policy experiments reported in this paper. The model builds on previous work (Mercenier 1995a, Mercenier and Akitoby 1993) using sound modern trade theory, and the policy issue under focus - whether it is advisable for Turkey to trade-integrate with Europe-is currently one of the most actively debated questions in that country.

The paper is organized as follows. Section 2 states the data problem. The policy questions and the applied GE framework are introduced in Section 3. Evidence is documented in Section 4 that trade policy prescriptions offered using the flawed data are potentially wrong. Section 5 is reserved for concluding comments. A formal presentation of the model is given in Appendix A. Some aspects of the data base, the calibration, and the computational strategy are discussed in Appendix B.

\section{The Data Problem}

Turkey's I-O data have been published at irregular, yet quite frequent, intervals by the State Institute of Statistics (SIS) with remarkably short lags; for instance, the most recent 1990 I-O data were published by early $1994 .{ }^{4}$ Clearly, this commitment to frequent and rapid publication of economic data by the Turkish authorities reflects a strong political willingness to foster discussion of important economic policy issues facing the nation. It also demonstrates a fairly sophisticated state of the data collection and processing technology. Yet, even the most basic data are repeatedly reported with obviously large biases and are regularly used without question by economists and researchers of the Turkish economy. Table 1 shows the share of wages and salaries in aggregate value added as they officially appear in the I-O tables for 1990 (SIS 1994) and the Manufacturing Industry Survey for 1990 (SIS 1995). Though the original sources distinguish 64 sectors of production, to conserve on space, we report here only the numbers for a few important representative activities and for the economy as a whole. The two sources report sizable differences, but consistently reveal unexpectedly low values: on average 32 percent in the former and 20 percent in the latter. Similar orders of magnitude are obtained from other sources, such as the Chamber of Industry Surveys of the 500 Largest Industrial Firms.

4 For the sake of comparison, the latest I-O data officially published in Belgium are for 1980. 
Clearly, if one were to accept these data at face value and characterize neoclassical production technologies accordingly, the Turkish economy would be two to three times more capital-intensive than the U.S. or the Japanese economy. (See Table 1.) Turkey would be avidly trading capital-intensive goods for Japanese or U.S. labor-intensive commodities! This is obviously counterfactual, and it is difficult to imagine how even heroic departures from neoclassical assumptions could be consistent with such numbers. There can be no doubt that the definitions used by Turkish statisticians differ substantially from those used by economists. In their current raw form, these data are clearly unfit for economic analysis, as will be shown in a later section.

\section{The Policy Questions and Analytical Framework}

Turkey has long held aspirations of becoming a full member of the former European Economic Community (EEC), now the European Union (EU). ${ }^{5}$ Despite the rejection of its official reapplication for full membership in April 1987, Turkey pursued its trade liberalization efforts vis-à-vis the EEC by reducing its sectoral tariffs on its European imports annually. In March 1995, both sides agreed to harmonize the Turkish tariff structure with that of the EU in a customs union that would be in effect by December 1995.

Not surprisingly, therefore, Turkish policy makers are keen to understand how and by how much the completion of the European Single Market will affect the Turkish economy. In this new international environment, the Turkish authorities face, among others, two important and actively debated questions:

(a) Is a complete tariff elimination vis-à-vis European partners welfare-improving? Or could such a policy be undesirable because of strongly distorted domestic markets?

(b) If Turkey were to join the European Single Market today-which would imply the elimination of all forms of tariff and nontariff barriers to trade with Europe-how important would the induced intersectoral and intertemporal resource reallocations be? And how welfareimproving would such a policy be for the country?

To answer these questions quantitatively, we introduce Turkey into the multicountry, multisector applied GE model built by Mercenier 1995a to study European integration issues.

5 Turkey's first official application to join the EEC was made as early as 1959. This led to the 1963 Ankara Agreement and the 1970 Added Protocol, which provided a specific blueprint of adjustment toward harmonization of the Turkish economy with its European counterparts. The relations suffered a stalemate between 1980 and 1986, as a result of the military coup of September 1980. 
The model recognizes that in some manufacturing sectors, firms use increasing returns to scale technologies and behave as Cournot oligopolies producing differentiated goods. We embed this detailed structure into an optimal growth framework along the lines of Mercenier and Akitoby 1993, and we make use of recent theoretical results on dynamic aggregation by Mercenier and Michel 1994a to apprehend transitional dynamic effects. Following is an overview of the model structure. A formal description is provided in the Appendices, as well as some discussion of the data and of calibration and computational procedures.

Turkey is part of a world economy consisting of itself and six other regions: Great Britain, the Federal Republic of Germany, France, Italy, the rest of the EU, and the rest of the world. Each country has nine sectors of production, of which four are perfectly competitive. ${ }^{6}$ In these sectors, countries are linked by an Armington system so that commodities are differentiated in demand by their geographical origin. The other five industries are modeled as noncompetitive. ${ }^{7}$ In the latter sectors, firms are assumed to be symmetric within national boundaries. They operate with fixed primary factor costs and therefore face increasing returns to scale in production. They have no monopsony power on any market for inputs, either primary or intermediate. Each individual oligopolist produces a different good. Industry structure is assumed fixed in the short run; oligopolistic firms may then experience nonzero profits. In the long run, however, entry and exit of competitors in a Chamberlinian fashion ensure that these rents vanish. The competitive game between oligopolistic firms is assumed to be Cournot-Nash. The instantaneous GE concept adopted is a compromise in terms of informational requirements between the primitive conjectural Cournot-Nash-Walras equilibrium of Negishi 1961 and the objective Cournot-Nash-Walras equilibrium introduced by Gabszewicz and Vial 1972. ${ }^{8}$ In all sectors, competitive and noncompetitive, a detailed country- and sector-specific system of price-responsive intermediate demands is specified that recognizes differences among products from individual oligopolistic suppliers à la Ethier 1982.

Final demand decisions are made in each country by a single representative household that is competitive, infinitely lived, and utility-maximizing. The domestic household owns all the country's primary factors, namely, labor and physical capital, which it rents to domestic firms

6 The four perfectly competitive sectors are agriculture and primary products; food, beverage, and tobacco; other manufacturing industries (textile, wood, paper, metallurgy and minerals); and transport and services.

7 The noncompetitive industries are pharmaceutical products; chemistry other than pharmaceutical products; motor vehicles; office machinery; and other machinery and transport materials.

8 Noncompetitive firms are endowed with full knowledge of the preferences and technologies of their clients, and they make use of this knowledge when maximizing profits. In their maximization, however, they neglect the feedback effect of their decisions on their profits via income (the Ford effect, see Gabszewicz and Vial 1972) and via input-output multipliers (the Nikaido effect, see Nikaido 1975). 
only, at the same competitive price regardless of the sector. In the short run, however, total returns to capital may differ across industries: oligopolistic profits may add to capital rental earnings because of unexpected shocks. We abstract from leisure/labor decisions and population growth so that the variables under household control are consumption and investment. In making optimal decisions subject to their intertemporal budget constraints, households can borrow or lend on international markets. All final demands recognize differences among products from individual oligopolistic firms à la Dixit and Stiglitz 1977.

The only explicit role of the government is to raise tariffs, the proceeds of which are rebated to domestic consumers lump-sum.

National markets are assumed to be segmented in the initial equilibrium: because of various more or less pernicious forms of nontariff barriers (NTBs) — such as norms, government procurement policies, security regulations-that prevent consumers from cross-border arbitraging, noncompetitive firms behave as price-discriminating oligopolists. Following Smith and Venables 1988, we implement the completion of the European Single Market by forcing firms to adopt a single pricing rule within Europe, determined on the basis of their average EU-wide monopoly power. The elimination of the possibility for firms to discriminate among client countries within the EU is interpreted as resulting from the removal of the NTBs underlying the initial price spread.

Central to our analysis is the measure of welfare gains, which we now make precise. Let $\widehat{C}(t)$ be the reference stream of consumption and $C(t)$ be the corresponding time profile computed after implementation at $t=0$ of a (previously unexpected) trade policy change. The welfare gain is determined from the following utility indifference condition:

$$
\int_{0}^{\infty} e^{-\rho t} \frac{[\hat{C}(t)(1+\phi)]^{1-\gamma}}{1-\gamma} d t=\int_{0}^{\infty} e^{-\rho t} \frac{C(t)^{1-\gamma}}{1-\gamma} d t .
$$

That is, the welfare gain resulting from the policy change is equivalent from the perspective of the representative Turkish household to increasing the reference consumption profile by $\phi$ percent. The measure $\phi$ accounts for both transitional and long-term effects of the policy on the household's well-being, putting relatively low weight on the latter because of discounting. It is sometimes useful to restrict the welfare analysis to steady-state effects, in particular when making comparisons with predictions from static models. To do this, we define $\lim _{t \rightarrow \infty} \widehat{C}(t)=\widehat{C}_{s s}$, 
$\lim _{t \rightarrow \infty} C(t)=C_{s s}$, and we plug these constant values into the utility indifference condition. Rearranging, we get

$$
\widehat{C}_{s s}\left(1+\phi_{s s}\right)=C_{s s}
$$

where $\phi_{s s}$ is the (equivalent variation) welfare measure most frequently used in static applied GE analysis.

\section{Unreliable Policy Prescriptions From Flawed Data}

Nominally at least, the European Single Market has been completed since January 1993. In practice, of course, the program will take some time to become fully implemented and indeed longer still before its effects can be observed in the data. Our first task is therefore to simulate the likely consequences of the European integration effort, that is, to set the new international environment in which Turkey has to make its future policy decisions. We do this simulation for two alternative characterizations of the Turkish production technologies, which we refer to as specifications 1 and 2 . In the first, we calibrate using the officially published factor shares, whereas in the second, we use 50 percent downwardly adjusted capital-income shares. ${ }^{9}$ As one could have expected, the effects on the Turkish economy of intra-European trade integration are extremely mild, and this is true whichever specification is used. To conserve space, we therefore do not dwell on this predominantly European issue, and we refer to Mercenier 1995a for extensive discussion. We report here only the welfare effects $\phi$, which are slightly negative with both specifications: respectively, -0.07 and -0.05 percent. These two solutions serve as competing benchmarks against which Turkish trade options are next to be evaluated.

The first policy option we consider is the elimination of all tariffs on imports from Europe. Table 2 shows the solution time profile of major aggregate variables. See also Figure 1. Under both technology specifications, trade liberalization induces a strong deterioration of the terms of trade, which shifts the profile of consumption downward. The wealth contraction is milder in the first case. Investment increases over the whole time horizon, however, despite the negative wealth shock. This is because consumers find it optimal to substitute future for current consumption, more so the more capital-intensive the technology is, since investment then yields higher returns. Hence, production capacities increase monotonously with the first specification, whereas with the second specification, the capital stock overshoots its new steady-state level during the transition. As a result, the long-term supply of capital services increases by 4.3 and

9 Note from Table 1 that this adjustment, though in appearance quite drastic, still leaves more than 35 percent of factor rewards to capital owners in the economy. 
1.5 percent, respectively. Rationalization of imperfectly competitive industries generates longterm aggregate efficiency gains (i.e., real cost savings achieved due to increased scale on initial output) by 3.7 and 2.8 percent. Despite these common features, the long-term effects of the policy are qualitatively different: the trade liberalization boosts consumption upward by half a percentage point ( $\phi_{s s}=0.59$ percent $)$ with the first specification, while cutting consumption by a similar amount ( $\phi_{s s}=-0.42$ percent) with the second specification. Hence, based on steady-state welfare, the recommendation built on official data is to eliminate tariffs on European imports-a policy actually recently adopted by Turkey_yet, implementation of more realistic technologies suggests that such a policy is not desirable. Reassuringly, if transitional dynamics are taken into account in the welfare analysis, the contradiction disappears. This is because the long-term increase in consumption predicted when unadjusted technologies are used is too small to compensate for the transitional costs, so that to be indifferent between the initial and the tariff-free equilibria, the Turkish household would need to be compensated by an amount equivalent to 0.66 percent of its consumption flow over the whole time horizon $(\phi=-0.66$ percent; with adjusted factor shares, $\phi=-0.91$ percent).

If Turkey were to join the European Single Market, it would have to get rid not only of tariffs but also of all forms of nontariff barriers. Table 3 and Figure 2 summarize the findings. Observe how little the elimination of NTBs affects the time profile of aggregate variables. Yet, the overall impact on the economy is quite substantial, independent of the factor shares used. The reason is found in sectors of activity initially dominated by inefficient local oligopolists. The opening up of domestic markets to international competition forces Turkish producers to cut prices in the domestic market - where they have large shares and, hence, strong monopoly power-and to move down along their average cost curve to face the induced expansion of demand. The efficiency gains hence achieved range between 12 and 18 percent; not surprisingly, they appear quite robust to the factor shares used for calibration. The cost-saving shock has a positive wealth effect that shifts the profile of consumption upward. It also induces more capital accumulation than was the case in the tariff-elimination-only experiment. As a result, steady-state consumption increases with both specifications of technologies $\left(\phi_{s s}=2.10\right.$ and 0.57 percent). This could suggest an unambiguous policy recommendation. It is not the case, however, since ambiguous welfare conclusions arise when transitional dynamics are taken into account. Based on official data, the analysis recommends that joining the European Single Market is desirable from a Turkish perspective ( $\phi=0.24$ percent). Yet, when conservatively adjusted factor-income ratios are used, the same analysis indicates that the long-term gains from the integration policy are too modest to compensate the representative Turkish household from the short-term adjustment costs $(\phi=-0.10$ percent $)$. 


\section{Conclusion}

We have highlighted an example of considerable bias in officially published data by an LDC. The country, Turkey, is likely to be above LDC averages in terms of the quality of its statistical system. The questioned data on factor income shares are among the most fundamental, as they characterize production technology that is at the heart of quantitative economic development and growth analysis. Yet, researchers recurrently use these flawed data when building policy recommendations, ignoring or unaware of the problem.

To demonstrate the potential seriousness of the problem, we have made use of a dynamic multisectoral applied GE model of the Turkish economy and shown how unreliable even qualitative answers are to such important policy questions as, Is trade liberalization desirable? The same verdict holds when the welfare analysis is restricted to steady-state comparisons or extended to account for transitional effects.

It is worth stressing that the example provided in this paper is by no means an isolated case: the same data problem has been identified for Mexico (Kehoe and Kehoe 1994) and apparently equally ignored by modelers in their appraisals of the potential welfare effects of the NAFTA. In view of these examples, the poignant message remains clear: whatever the sophistication of the analysis, it is only worth the quality of the supporting data it utilizes. 


\section{References}

Boratav, K., O. Turel and E. Yeldan, 1994, "Distributional Dynamics in Turkey under 'Structural Adjustment' of the 1980's," New Perspectives on Turkey, Fall (11),.43-70.

Brooke, A., D. Kendrick and A. Meeraus, 1988, GAMS: A User's Guide. San Francisco: Scientific Press.

Bulutay, T., 1993, "Seminar on Employment, Unemployment and Wages in Turkey," State Institute of Statistics, Ankara.

Celasun, M., 1989, "Income Distribution and Employment Aspects of Turkey's Post-1980 Adjustment," METU Studies in Development 16 (3-4), 1-32.

Dixit, A.K. and J.E. Stiglitz, 1977, "Monopolistic Competition and Optimum Product Diversity," American Economic Review 67, 297-308.

Ethier, W.J., 1982, "National and International Returns to Scale in the Modern Theory of International Trade," American Economic Review 72, 389-405.

Gabszewicz, J.J. and J.P. Vial, 1972, "Oligopoly 'à la Cournot' in a General Equilibrium Analysis," Journal of Economic Theory 4, 381-400.

Go, D., 1994, "External Shocks, Adjustment Policies and Investment in a Developing Economy: Illustrations from a Forward-Looking CGE Model of the Philippines," Journal of Development Economics 44, 229-261.

Harrison, G., T. Rutherford and D. Tarr, 1993, "Trade Reform in the Partially Liberalized Economy of Turkey," World Bank Economic Review 7 (2), 191-217.

Kaytaz, M., S. Altin and M. Gunes, 1993, "Turkiye Imalat Sanayiinde Yogunlasma" (Concentration in the Turkish Manufacturing Industry), TMMOB, 1993 Sanayi Odasi Bildiriler Kitabi 1 (160).

Kehoe, P. and T. Kehoe, 1994, "Capturing NAFTA's Impact With Applied General Equilibrium Models," Federal Reserve Bank of Minneapolis Quarterly Review, Spring, 17-33. (Also in: Kehoe, P. and T. Kehoe, eds., Modeling North American Economic Integration. Boston: Kluwer Academic Publishers, 1995.)

Mercenier, J., 1995a, "Can '1992' Reduce Unemployment in Europe? On Welfare and Employment Effects of Europe's Move to a Single Market," Journal of Policy Modeling 17 (1), 1-37.

Mercenier, J., 1995b, "Nonuniqueness of Solutions in Applied General Equilibrium Models with Scale Economies and Imperfect Competition," Economic Theory 6, 161-177.

Mercenier, J. and B. Akitoby, 1993, "On Intertemporal General-Equilibrium Reallocation Effects of Europe's Move to a Single Market," Institute for Empirical Macroeconomics Working Paper 87, Federal Reserve Bank of Minneapolis. 
Mercenier, J. and P. Michel, 1994a, "Discrete Time Finite Horizon Approximation of Optimal Growth with Steady State Invariance," Econometrica 62, 635-656.

Mercenier, J. and P. Michel, 1994b, "A Criterion for Time Aggregation in Intertemporal Dynamic Models," Mathematical Programming 64, 179-197.

Mercenier, J. and M.C. Sampaio de Souza, 1994, "Structural Adjustment and Growth in a Highly Indebted Economy: Brazil", in J. Mercenier and T.N. Srinivasan, eds., Applied General Equilibrium Analysis and Economic Development : Present Achievements and Future Trends, Ann Harbor: University of Michigan Press, 281-310.

Ministry of International Trade and Industry (MITI), 1989, The 1985 Japan-U.S. Input-Output Table. Tokyo.

Negishi, T., 1961, "Monopolistic Competition and General Equilibrium," Review of Economic Studies 28, 196-201.

Nikaido, H., 1975, Monopolistic Competition and Effective Demand. Princeton, N.J.: Princeton University Press.

Ozmucur, S., 1991, "Girdi/Cikti Tablolarindan Elde Edilen Faktor Gelirlerinin Dagilimi" (Distribution of Factor Incomes Based on Input-Output Tables), Bogazici University Research Paper SBE/EC 91-11.

Senses, F., 1990, "Turkiye'de Gelir Dagilimi, Gelirin Yeniden Dagitimi ve Isgucu Piyasalari" (Distribution and Re-disribution of Income and Labor Markets in Turkey), Middle East Technical University Working Paper ERC/19903.

State Institute of Statistics (SIS), 1995, Statistical Yearbook of Turkey. Ankara.

State Institute of Statistics (SIS), 1994, The Input Output Structure of the Turkish Economy 1990. Ankara.

State Institute of Statistics (SIS), 1993, Concentration in the Turkish Manufacturing Industry, 1985-1989. Ankara.

Smith, A. and A.J. Venables, 1988, "Completing the Internal Market in the European Community: Some Industry Simulations," European Economic Review 32, 1501-1525.

Srinivasan, T.N., 1994a, "Introduction," Journal of Development Economics 44 (1), 1-2.

Srinivasan, T.N., 1994b, "Data Base for Development Analysis: An Overview," Journal of Development Economics 44 (1), 3-27.

Stokey, N., 1994, "NAFTA and Mexican Development," mimeo, University of Chicago (August).

Temel, A., 1993, "1980'li Yillarda Turk Dis Ticaret Refini ve Dis Ticaretir Liberalizasyonu" (Turkish Foreign Trade Regime and Its Liberalization in the 1980's), Turk Eximbank, Ankara. 
Togan, S., 1993, "How to Assess the Significance of Export Incentives: An Application to Turkey," Welwirtschafliches Archives.

Yeldan, E., 1995, "Political Economy Perspectives on the 1994 Turkish Economic Crisis: A CGE Modeling Analysis," University of Minnesota Economic Development Center Bulletin 95-3 (March). 


\section{Appendix A: The Model}

Turkey $(T R)$ is part of a world economy consisting of itself and six other regions: Great Britain, the Federal Republic of Germany, France, Italy, the rest of the EU, and the rest of the world.

1 The dynamic structure

In each country, there is a single representative household, that is competitive, infinitely lived, and utility-maximizing. The domestic household owns all the country's primary factors, namely, labor and physical capital, which it rents to domestic firms only, at competitive prices $w$ and $r$, respectively. (For notational convenience, we drop the country subscript in this subsection.) We abstract from leisure/labor decisions and population growth so that labor is in fixed supply $L$. The decision variables of the household are consumption $C$ and investment $I$. In making these optimal decisions, the household has access to international financial markets on which it can borrow or lend. Its intertemporal decision problem is to maximize

(A.1) $\int_{0}^{\infty} e^{-\rho t} \frac{C(t)^{1-\gamma}}{1-\gamma} d t$

subject to

(A.3) $\quad \int_{0}^{\infty} e^{-\rho t}\left[p_{c}(t) C(t)+p_{I}(t) I(t)\right] d t \leq$

$$
\int_{0}^{\infty} e^{-\rho t}\left[w(t) L(t)+r(t) K(t)+\sum_{s} \pi_{s}(t)+G(t)\right] d t+F(0)
$$

$K(0), F(0)$ given.

Equation (A.2) accounts for capital accumulation with exponential depreciation. Equation (A.3) is the household's intertemporal budget constraint. It specifies that the sum of discounted stream of consumption and investment expenditures (for convenience, all prices are defined as undiscounted) cannot exceed the discounted sum of revenues earned from primary factor ownership and government transfers $G(t)$ plus initial holding of foreign assets $F(0)$. The term $\Sigma_{s} \pi_{s}(t)$ in the budget constraint accounts for the possibility that, in the short run, because of 
unexpected shocks to imperfectly competitive industries, supranormal profits may add to capital rental earnings. All countries have the same constant discount rates $\rho$.

2 The instantaneous equilibrium structure

We now neglect the time index. We identify sectors of activity by indices $s$ and $t$, with $S$ representing the set of all industries, so that $s, t=1, \ldots, S$. The set $S$ is partitioned into the subset of competitive, constant returns to scale sectors, denoted $C$, and the subset of noncompetitive, increasing returns to scale industries, denoted $\bar{C} .10$ Countries are identified by indices $i$ and $j$, with $i, j=1, \ldots, W$ and $W=E U \cup T R \cup R O W$, where $E U$ represents the European Union, and $R O W$ represents the rest of the world. We keep track of the trade flows by following the usual practice that identifies the first two indices with, respectively, the country and the industry supplying the good and, when appropriate, the next two with the client country and industry. ${ }^{11}$

The household

For exposition ease, we break household $i$ 's static decision making into a consumer and an investor choice problem. This breakage is innocuous, given our separability assumptions on preferences and investment technologies. The domestic consumer values products of competitive industries from different countries as imperfect substitutes (the Armington assumption), while the consumer treats as specific each good produced by individual firms operating in the noncompetitive industries (the Dixit-Stiglitz 1977 specification). We use a two-level utility function. The first level combines consumption goods $c_{. s i}$ and assumes constant expenditure shares $\rho_{s i}$. The second level determines the optimal composition of the consumption aggregates in terms of geographical origin for competitive industries or in terms of the individual firm's product for the noncompetitive sectors. Formally, the consumer's preferences are

$$
\begin{aligned}
& \log C_{i}=\sum_{s \in S} \rho_{s i} \log c_{. s i}, \quad \quad \sum_{s \in S} \rho_{s i}=1, \\
& \text { (A.4) } c_{. s i}=\left\{\sum_{j \in W} \delta_{j s i}^{c} c_{j s i}^{\frac{\sigma_{s}-1}{\sigma_{s}}}\right\}^{\frac{\sigma_{s}}{\sigma_{s}-1}}, \quad s \in C \text {, } \\
& c_{. s i}=\left\{\sum_{j \in W} n_{j s} \delta_{j s i}^{c} c_{j s i} \frac{\sigma_{s}^{f}-1}{\sigma_{s}^{f}}\right\}^{\frac{\sigma_{s}^{f}}{\sigma_{s}^{f}-1}}, \quad s \in \bar{C},
\end{aligned}
$$

10 Though $C$ also denotes aggregate consumption, no confusion can arise.

11 Thus, a subscript $i s j t$ indicates a flow originating in country $i$, sector $s$ with country $j$, sector $t$ as the destination. 
where $\delta_{j s i}^{c}$ denotes the share parameters, $\sigma_{s}$ denotes the Armington substitution elasticities, $\sigma_{s}^{f}$ denotes the Dixit-Stiglitz differentiation elasticities, and $n_{j s}$ denotes the number of symmetric oligopolists operating in country $j$, sector $s .{ }^{12}$ Observe that when $s \in C, c_{j s i}$ denotes the sales to the consumer of the whole industry $s$ of country $j$, whereas when $s \in \bar{C}$, it represents the sales of a single representative firm. The interpretation of the two elasticities $\sigma_{s}$ and $\sigma_{s}^{f}$ is therefore very different: the latter will typically be larger than the former. For goods that are nontraded we have $\delta_{j s i}^{c}=0 \forall j \neq i$.

The consumer maximizes (A.4) with respect to $c_{j s i}$, subject to

$$
p_{c i} C_{i} \geq \sum_{j \in W}\left(\sum_{s \in C}\left(1+\tau_{j s i}\right) p_{j s i} c_{j s i}+\sum_{s \in \bar{C}}\left(1+\tau_{j s i}\right) p_{j s i} n_{j s} c_{j s i}\right)
$$

where $\tau_{j s i}$ is tariff rates, $p_{j s i}$ is prices on which consumers have no influence, and the term on the left side results from the intertemporal decision of the household.

The investor's problem is to determine the optimal composition of the domestic investment good; for this, the investor maximizes (A.6) with respect to $I_{j s i}$ :

$$
\begin{aligned}
\log I_{i} & =\sum_{s \in S} \omega_{s i} \log I_{. s i}, & \sum_{s \in S} \omega_{s i}=1, \\
(\mathrm{~A} .6) \quad I_{. s i} & =\left\{\sum_{j \in W} \delta_{j s i}^{I} I_{j s i}^{\frac{\sigma_{s}-1}{\sigma_{s}}}\right\}^{\frac{\sigma_{s}}{\sigma_{s}-1},} & s \in C, \\
I_{. s i} & =\left\{\sum_{j \in W} n_{j s} \delta_{j s i}^{I} I_{j s i} \frac{\sigma_{s}^{f}-1}{\sigma_{s}^{f}}\right\}^{\frac{\sigma_{s}^{f}}{\sigma_{s}^{f}-1},} & s \in \bar{C},
\end{aligned}
$$

subject to

$$
\text { (A.7) } p_{I i} I_{i} \geq \sum_{j \in W}\left(\sum_{s \in C}\left(1+\tau_{j s i}\right) p_{j s i} I_{j s i}+\sum_{s \in \bar{C}}\left(1+\tau_{j s i}\right) p_{j s i} n_{j s} I_{j s i}\right)
$$

where, again, $\tau_{j s i}$ is tariff rates, $p_{j s i}$ is prices which investors take as given, and the term on the left side results from the intertemporal decision of the household. Observe that the share parameters $\delta_{j s i}^{c}$ and $\delta_{j s i}^{I}$ in (A.4) and (A.6) are specific to each decision problem, so that price

12 The symmetry assumption implies that imperfectly competitive domestic firms within a sector have the same cost structure and market shares. 
responsiveness of the two final demand components will differ, even though the consumer and the investor are assumed to have the same substitution and differentiation elasticities ( $\sigma_{s}$ and $\left.\sigma_{s}^{f}\right)$ since no econometric information is available on potential differences.

\section{The Firms}

a) Competitive industries. In competitive industries, the representative firm of country $i$, sector $s$ operates with constant returns to scale technologies, combining variable capital $K_{i s}^{v}$ and labor $L_{i s}^{v}$ as well as intermediate inputs $x_{j t i s}$. Material inputs are introduced into the production function in a way similar to the way consumption goods are treated in the preferences of households: with an Armington specification for goods produced by competitive industries and with an Ethier 1982 specification, i.e., with product differentiation at the firm level, in the imperfectly competitive sectors. Input demands by country $i$ 's representative producer of sector $s \in C$ result from the minimization of the variable unit cost $v_{i s}$ :

$$
\text { (A.8) } v_{i s} Q_{i s}=\sum_{j \in W}\left(\sum_{t \in C}\left(1+\tau_{j t i}\right) p_{j t i} x_{j t i s}+\sum_{t \in \bar{C}}\left(1+\tau_{j t i}\right) p_{j t i} n_{j t} x_{j t i s}\right)+w_{i} L_{i s}^{v}+r_{i} K_{i s}^{v}
$$

for a given level of output $Q_{i s}$, such that

$$
\begin{aligned}
& \log Q_{i s} \leq \alpha_{L i s} \log L_{i s}^{v}+\alpha_{K i s} \log K_{i s}^{v}+\sum_{t \in S} \alpha_{t i s} \log x_{. t i s} \\
& \text { (A.9) } x_{. t i s}=\left\{\sum_{j \in W} \beta_{j t i s} x_{j t i s} \frac{\sigma_{t}-1}{\sigma_{t}}\right\}^{\frac{\sigma_{t}}{\sigma_{t}-1}}, \quad t \in C \text {, } \\
& x_{. t i s}=\left\{\sum_{j \in W} n_{j t} \beta_{j t i s} x_{j t i s}^{\frac{\sigma_{t}^{x}-1}{\sigma_{t}^{x}}}\right\}^{\frac{\sigma_{t}^{x}}{\sigma_{t}^{x}-1}}, \quad t \in \bar{C},
\end{aligned}
$$

where the $\alpha$ s and the $\beta$ s are share parameters with

$$
\alpha_{L i s}+\alpha_{K i s}+\sum_{t \in S} \alpha_{t i s}=1
$$

$\beta_{j t i s}=0 \forall j \neq i$ if $t$ is nontraded, and $\sigma_{s}$ and $\sigma_{s}^{x}$ have the same interpretations as $\sigma_{s}$ and $\sigma_{s}^{f}$ in (A.4) and (A.6). Though there is no reason to expect that final and intermediate demanders differentiate identically products from different firms, we assume that $\sigma_{s}^{x}=\sigma_{s}^{f}$ in absence of econometric information on these differences. 
Cost minimization implies marginal cost pricing $\left(p_{i s j}=v_{i s}\right)$ and zero profits $\left(\pi_{i s}=0\right)$ in the competitive sectors.

b) Noncompetitive industries. Noncompetitive industries have increasing returns to scale in production. We model this by assuming that in addition to variable costs associated with technological constraints similar to (A.8) and (A.9), the individual firms in country $i$, sector $s$ face fixed primary factor costs. This introduces a wedge between total unit costs $V_{i s}$ and marginal $\operatorname{costs} v_{i s}$ :

(A.10) $V_{i s}=v_{i s}+\frac{\left[w_{i} L_{i s}^{F}+r_{i} K_{i s}^{F}\right]}{Q_{i s}}, \quad s \in \bar{C}$,

where $Q_{i s}, L_{i s}^{F}$ and $K_{i s}^{F}$ denote, respectively, the individual firm's output, fixed labor, and fixed capital.

Because of the presence of various forms of nontariff barriers, national economies are assumed initially segmented. The noncompetitive firm facing demand segmentation takes advantage of the monopoly power it has on each individual country market. For this purpose, the firm is endowed with the knowledge of preferences (A.4) and technologies (A.6) through (A.9) of its clients. It then performs a partial equilibrium profit maximization calculation assuming that in each country, each individual client's current-price expenditure on the whole industry is unaffected by its own strategic action $z_{i s j}$, so that

$$
\begin{aligned}
\frac{\partial\left(\rho_{s j} p_{c j} C_{j}\right)}{\partial z_{i s j}} & =0, \quad j \in W, \\
\frac{\partial\left(\omega_{s j} p_{I j} I_{j}\right)}{\partial z_{i s j}} & =0, \quad j \in W, \\
\frac{\partial\left(\alpha_{s j t} v_{j t} Q_{j t}\right)}{\partial z_{i s j}} & =0, \quad j \in W, t \in S .
\end{aligned}
$$

We make the Cournot assumption of noncooperative behavior with sales to each individual market as the strategic variable $z_{i s j}$. Profit maximization then yields that

$$
\frac{p_{i s j}-v_{i s}}{p_{i s j}}=\frac{\partial \log p_{i s j}}{\partial \log z_{i s j}}, \quad s \in \bar{C}, j \in W
$$

with

(A.13) $Q_{i s}=\sum_{j \in W} z_{i s j}$ 
The computation of the elasticities on the right side of (A.12) requires inverting log-linearized aggregate demand systems. This is a very complex calculation, the details of which are given in Mercenier 1995b.

The definition of oligopolistic industry profits then immediately follows:

$$
\text { (A.14) } \pi_{i s}=n_{i s}\left(\sum_{j \in W} p_{i s j} z_{i s j}-V_{i s} Q_{i s}\right), \quad s \in \bar{C} \text {. }
$$

$\underline{\text { The static equilibrium conditions }}$

The instantaneous GE is defined as a static allocation supported by a vector of prices $\left(p_{i s j}, w_{i}, r_{i}\right), s \in S$, and $i, j \in W$ consistent with the intertemporal constraints and choices in (A.1) through (A.3) and such that

- Tariff revenues are rebated to consumers lump-sum:

$$
G_{i}=\sum_{j \in W}\left(\sum_{s \in C} \tau_{j s i} p_{j s i}\left(c_{j s i}+I_{j s i}+\sum_{t \in S} x_{j s i t}\right)+\sum_{s \in \bar{C}} \tau_{j s i} p_{j s i} n_{j s}\left(c_{j s i}+I_{j s i}+\sum_{t \in S} x_{j s i t}\right)\right)
$$

- Consumers maximize (A.4) subject to (A.5);

- Investors maximize (A.6) subject to (A.7);

- Firms minimize (A.8) subject to (A.9);

- Oligopolistic firms set prices according to (A.12) and satisfy the resulting demand so that

(A.16)

$$
z_{i s j}=c_{i s j}+I_{i s j}+\sum_{t \in S} x_{i s j t}, \quad s \in \bar{C}, i, j \in W
$$

and (A.13) holds;

- Supply equals demand on each competitive market:

(A.17) $Q_{i s}=\sum_{j \in W}\left[c_{i s j}+I_{i s j}+\sum_{t \in S} x_{i s j t}\right], \quad s \in C, i \in W$

(A.18) $K_{i}=\sum_{s \in C} K_{i s}^{v}+\sum_{s \in \bar{C}} n_{i s}\left[K_{i s}^{v}+K_{i s}^{F}\right], \quad i, j \in W$; 
(A.19) $L_{i}=\sum_{s \in C} L_{i s}^{v}+\sum_{s \in \bar{C}} n_{i s}\left[L_{i s}^{v}+L_{i s}^{F}\right], \quad i, j \in W$

- Industry concentration $n_{i s}>1(s \in \bar{C}$, and $i \in W)$, adjusts with inertia to the existence of nonnegative oligopoly rents so that, in the long run, these rents are null. The process of entry and exit of firms is implemented in the following way:

$$
n_{\text {is }}(0) \text { given, } n_{i s}(\infty) \text { such that } \pi_{i s}(\infty)=0 \text {, }
$$

$$
\dot{n}_{i s}(t)=\theta\left[n_{i s}(\infty)-n_{i s}(0)\right], 0<\theta<1 .
$$

The first period $R O W$ wage rate is chosen as the numeraire. 


\section{Appendix B: Data, Calibration, and Computational Strategy}

1 The data

Data on the Turkish economy is compiled from the 1990 Input-Output Table of SIS 1994. To achieve sectoral consistency with the European counterparts as laid out in Mercenier 1995a, the original sectoral structure of the Turkish I-O Table, which consists of 64 production sectors, is aggregated to 9. Data on sectoral gross tariffs, as well as final demand structure, are also derived from the same source. The tariff data clearly do not represent the official rates of tariffication, but rather give the actual revenues of the government that have accrued to the central budget. The effective rate of protection of the Turkish tariffication system, which is well beyond the subject of this paper, is examined in detail in Togan 1993.

Data on concentration ratios of the Turkish manufacturing industry are mainly derived from the SIS 1993. See also Kaytaz et al. 1993 for a characterization of the organizational structure of the Turkish industry. The number of Chamberlinian symmetric firms in each imperfectly competitive industry is derived from the Herfindahl indices, which are reported therein.

2 Calibration and computation

The calibration procedure for the instantaneous GE is extensively discussed in Mercenier 1995a. We avoid duplication and focus our discussion on the treatment of dynamics.

We first note that the budget constraint (A.3) can be equivalently written in the following differential form:

$$
\begin{aligned}
& \dot{F}(t)=\rho F(t)+w(t) L(t)+r(t) K(t)+\sum_{s} \pi_{s}(t)+G(t)-\left[p_{c}(t) C(t)+p_{I}(t) I(t)\right], \\
& F(0) \text { given, } \lim _{t \rightarrow \infty} e^{-\rho t} F(t)=0,
\end{aligned}
$$

where again we neglect country subscripts for notational ease. We next make use of results by Mercenier and Michel 1994a on dynamic aggregation and write the following finite-horizon discrete-time approximation to the individual household's intertemporal choice problem:

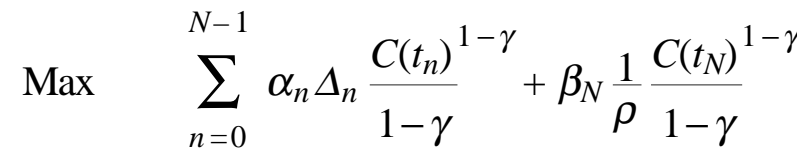

such that 


$$
\begin{aligned}
& F\left(t_{n+1}\right)-F\left(t_{n}\right)= \\
& \Delta_{n}\left[\rho F\left(t_{n}\right)+w\left(t_{n}\right) L\left(t_{n}\right)+r\left(t_{n}\right) K\left(t_{n}\right)+\sum_{s} \pi_{s}\left(t_{n}\right)+G\left(t_{n}\right)-p_{c}\left(t_{n}\right) C\left(t_{n}\right)-p_{I}\left(t_{n}\right) I\left(t_{n}\right)\right], \\
& K\left(t_{n+1}\right)-K\left(t_{n}\right)=\Delta_{n}\left[I\left(t_{n}\right)-\delta K\left(t_{n}\right)\right], \\
& F\left(t_{0}\right), K\left(t_{0}\right) \text { given, }
\end{aligned}
$$

where $t_{n}(n=0, \ldots, N)$ are possibly unequally spaced dates, $\Delta_{n}=t_{n+1}-t_{n}$, and $\alpha_{n}$ and $\beta_{N}$ are (unknown) discount factors. Proposition 2 of Mercenier and Michel 1994a ensures that this dynamic aggregation satisfies the property of steady-state invariance (i.e., a stationary equilibrium of (A.1) through (A.3) is also a constant solution of the time-aggregated approximation) if and only if the discount factors $\alpha_{n}$ and $\beta_{N}$ satisfy

$$
\begin{aligned}
\alpha_{n+1} & =\frac{\alpha_{n}}{\left(1+\rho \Delta_{n+1}\right)}, \quad o \leq n \leq N-2, \\
\beta_{N} & =\alpha_{N-1} .
\end{aligned}
$$

Assuming the world economy initially is in steady-state, ${ }^{13}$ these results make the calibration of the intertemporal equilibrium straightforward using the following first-order conditions:

$$
\begin{aligned}
{\left[\frac{C\left(t_{n-1}\right)}{C\left(t_{n}\right)}\right]^{-\gamma} } & =\frac{p_{c}\left(t_{n-1}\right)}{p_{c}\left(t_{n}\right)}, \quad 0<n \leq N, \\
p_{I}\left(t_{n-1}\right) & =\frac{1}{1+\rho \Delta_{n}}\left[\Delta_{n} r\left(t_{n}\right)+\left(1-\delta \Delta_{n}\right) p_{I}\left(t_{n}\right)\right], \quad 0<n<N, \\
p_{I}\left(t_{N}\right) & =\frac{1}{\rho}\left[r\left(t_{N}\right)-\delta p_{I}\left(t_{N}\right)\right] .
\end{aligned}
$$

We solve the model on a horizon of 35 years using five unequally distant grid dates: $t_{0}=1, t_{1}=5$, $t_{2}=10, t_{3}=20$, and $t_{N}=t_{4}=35$. Though the time-aggregation bias is obviously unknown-to evaluate this would require solving the system on a dense time grid, which is not possible given the size of the model—results reported in Mercenier and Michel 1994a, 1994b suggest that such approximations are quite accurate.

13 Though unrealistic for most LDCs, the steady-state assumption is systematically adopted in applied intertemporal GE models (e.g., Go 1994), in particular, because it is extremely convenient for calibration. The only effort at departure from this assumption in a large-scale model that we are aware of is by Mercenier and Sampaïo de Souza 1994, who calibrate a small open economy—Brazil—on a transition path. (For a similar effort in a one-sector growth model, see Stokey 1994.) Whether the additional complication is useful is still an open question. 
In the time-aggregated framework, the welfare criterion becomes the following: Determine $\phi$ such that

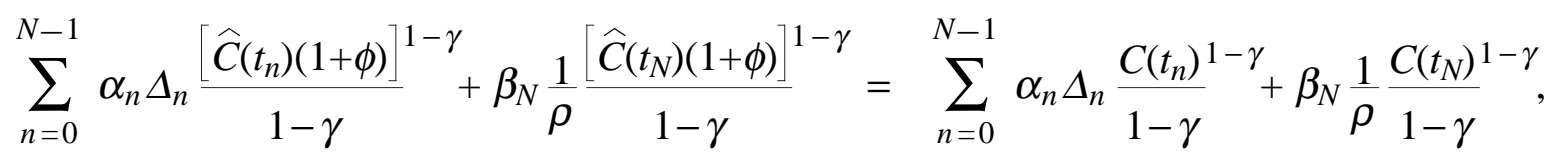

where $\widehat{C}\left(t_{n}\right)$ and $C\left(t_{n}\right), n=0, \ldots, N$ denote respectively, the benchmark and counterfactual equilibrium profiles of aggregate consumption.

Reduced as it is by dynamic aggregation, the dimensionality of this five-period model is still a numerical challenge. To overcome this problem, we build on Negishi's 1961 existence proof of an imperfectly competitive GE. We first exogenize oligopolistic markups and solve for the intertemporal equilibrium allocations, prices, and industry structures. ${ }^{14}$ Using these newly computed prices and market shares, we then upgrade the optimal markups. We iterate GaussSeidel way until convergence to a fixed point.

This numerical procedure proved quite reliable, and no computational difficulty is worth reporting. Nevertheless, there is little control on the search path with such a strategy, and no serious exploration of the possible existence of more than one equilibrium is possible. This is particularly unpleasant in view of the recent results of Mercenier 1995b, which suggest that in this generation of applied GE models, multiple equilibria can exist. It should be emphasized, however, that even though the structure of the instantaneous GE equilibrium of this model bears strong similarities to that of Mercenier 1995b, the treatment of factor markets differs substantially: we do not assume here that factors and factor owners move internationally. Though there is no reason to believe that the change eliminates the risk of nonuniqueness, numerical tests with Mercenier's $1995 \mathrm{~b}$ model suggest that the risk is actually reduced.

14 All computations have been performed using GAMS/MINOS (Brooke et al. 1988). 
Table 1: Sectoral labor shares (\%) in value added: Turkey, the United States, and Japan compared

\begin{tabular}{|l|c|c|c|c|}
\hline \multirow{2}{*}{ Sample sectors } & \multicolumn{2}{|c|}{ Turkey } & United States \\
$1985{ }^{c}$ & $\begin{array}{c}\text { Japan } \\
1985{ }^{c}\end{array}$ \\
\hline Food processing & 28.4 & 24.1 & 49.9 & 57.7 \\
\hline Textiles & 27.1 & 27.0 & 80.9 & 74.8 \\
\hline Paper and pulp & 38.9 & 24.5 & 64.4 & 59.2 \\
\hline Industrial chemicals & 52.1 & 23.5 & 65.0 & 45.3 \\
\hline Non-ferrous metals & 30.2 & 32.4 & 84.4 & 50.7 \\
\hline Metal products & 28.4 & 22.0 & 72.0 & 66.6 \\
\hline Machinery (except electrical) & 31.3 & 31.9 & 79.3 & 57.9 \\
\hline Electrical machinery & 35.1 & 22.3 & 79.2 & 55.8 \\
\hline Transport equipment (vehicles, etc.) & 45.2 & 30.6 & 82.3 & 57.9 \\
\hline Average for the whole economy & 32.4 & 20.3 & 49.6 & 66.1 \\
\hline
\end{tabular}

a Input-Output Tables. Source: SIS 1994.

b Manufacturing Industry Survey. Source: SIS 1995.

c Source: MITI 1989. (We thank Hiro Lee for kindly providing these numbers.) 


\section{Table 2: Elimination of all tariffs on European goods}

( $\%$ deviations from benchmark)

\section{Specification 1: Technologies calibrated on official factor shares}

Welfare gains: $\phi=-0.66 \%$

\begin{tabular}{|c|c|c|c|c|c|c|c|c|c|}
\hline $\begin{array}{c}\text { Time } \\
\text { (years) }\end{array}$ & $\begin{array}{c}\text { Wage } \\
\text { rate }\end{array}$ & $\begin{array}{c}\text { Rental rate } \\
\text { of capital }\end{array}$ & $\begin{array}{c}\text { Price of } \\
\text { consumption }\end{array}$ & Consumption & $\begin{array}{c}\text { Price of } \\
\text { investment }\end{array}$ & Investment & $\begin{array}{c}\text { Capital } \\
\text { stock }\end{array}$ & $\begin{array}{c}\text { Terms of } \\
\text { trade }\end{array}$ & $\begin{array}{c}\text { Aggregate } \\
\text { efficiency }\end{array}$ \\
\hline 1 & -7.33 & -7.18 & -8.91 & -2.15 & -9.74 & 10.92 & 0.00 & -8.70 & -4.76 \\
\hline 5 & -7.25 & -8.60 & -9.68 & -1.33 & -10.44 & 9.85 & 1.56 & -9.47 & -2.56 \\
\hline 10 & -7.49 & -9.94 & -10.48 & -0.45 & -11.15 & 6.24 & 2.74 & -10.26 & -0.63 \\
\hline 20 & -7.65 & -10.98 & -11.04 & 0.18 & -11.64 & 4.93 & 3.74 & -10.80 & 1.48 \\
\hline 35 & -8.01 & -11.72 & -11.40 & 0.59 & -11.94 & 4.26 & 4.26 & -11.15 & 3.69 \\
\hline
\end{tabular}

Specification 2: Technologies calibrated on adjusted factor shares

Welfare gains: $\quad \phi=-0.91 \%$

\begin{tabular}{|c|c|c|c|c|c|c|c|c|c|}
\hline $\begin{array}{c}\text { Time } \\
\text { (years) }\end{array}$ & $\begin{array}{c}\text { Wage } \\
\text { rate }\end{array}$ & $\begin{array}{c}\text { Rental rate } \\
\text { of capital }\end{array}$ & $\begin{array}{c}\text { Price of } \\
\text { consumption }\end{array}$ & Consumption & $\begin{array}{c}\text { Price of } \\
\text { investment }\end{array}$ & Investment & $\begin{array}{c}\text { Capital } \\
\text { stock }\end{array}$ & $\begin{array}{c}\text { Terms of } \\
\text { trade }\end{array}$ & $\begin{array}{c}\text { Aggregate } \\
\text { efficiency }\end{array}$ \\
\hline 1 & -8.01 & -7.97 & -9.52 & -1.67 & -10.30 & 4.21 & 0.00 & -9.30 & -4.19 \\
\hline 5 & -8.12 & -9.97 & -10.08 & -1.05 & -10.80 & 3.21 & 1.93 & -9.87 & -2.35 \\
\hline 10 & -8.38 & -10.79 & -10.37 & -0.74 & -11.05 & 2.24 & 2.53 & -10.15 & -1.19 \\
\hline 20 & -8.87 & -11.07 & -10.51 & -0.57 & -11.16 & 1.74 & 2.26 & -10.32 & 0.40 \\
\hline 35 & -9.65 & -11.22 & -10.65 & -0.42 & -11.28 & 1.55 & 1.55 & -10.51 & 2.85 \\
\hline
\end{tabular}


Table 3: Full integration in the European Single Market

(\% deviations from benchmark)

Specification 1: Technologies calibrated on official factor shares

Welfare gains: $\phi=+0.24 \%$

\begin{tabular}{|c|c|c|c|c|c|c|c|c|c|}
\hline $\begin{array}{c}\text { Time } \\
\text { (years) }\end{array}$ & $\begin{array}{c}\text { Wage } \\
\text { rate }\end{array}$ & $\begin{array}{c}\text { Rental rate } \\
\text { of capital }\end{array}$ & $\begin{array}{c}\text { Price of } \\
\text { consumption }\end{array}$ & Consumption & $\begin{array}{c}\text { Price of } \\
\text { investment }\end{array}$ & Investment & $\begin{array}{c}\text { Capital } \\
\text { stock }\end{array}$ & $\begin{array}{c}\text { Terms of } \\
\text { trade }\end{array}$ & $\begin{array}{c}\text { Aggregate } \\
\text { efficiency }\end{array}$ \\
\hline 1 & -4.99 & -4.68 & -7.63 & -1.97 & -8.53 & 16.00 & 0.00 & -7.27 & 7.52 \\
\hline 5 & -4.83 & -6.81 & -8.78 & -0.75 & -9.57 & 14.51 & 2.29 & -8.41 & 10.22 \\
\hline 10 & -5.16 & -8.83 & -9.98 & 0.57 & -10.65 & 9.17 & 4.02 & -9.58 & 12.62 \\
\hline 20 & -5.33 & -10.39 & -10.81 & 1.50 & -11.39 & 7.27 & 5.49 & -10.38 & 15.52 \\
\hline 35 & -5.70 & -11.50 & -11.33 & 2.10 & -11.83 & 6.26 & 6.26 & -10.86 & 19.14 \\
\hline
\end{tabular}

Specification 2: Technologies calibrated on adjusted factor shares

Welfare gains: $\phi=-0.10 \%$

\begin{tabular}{|c|c|c|c|c|c|c|c|c|c|}
\hline $\begin{array}{c}\text { Time } \\
\text { (years) }\end{array}$ & $\begin{array}{c}\text { Wage } \\
\text { rate }\end{array}$ & $\begin{array}{c}\text { Rental rate } \\
\text { of capital }\end{array}$ & $\begin{array}{c}\text { Price of } \\
\text { consumption }\end{array}$ & Consumption & $\begin{array}{c}\text { Price of } \\
\text { investment }\end{array}$ & Investment & $\begin{array}{c}\text { Capital } \\
\text { stock }\end{array}$ & $\begin{array}{c}\text { Terms of } \\
\text { trade }\end{array}$ & $\begin{array}{c}\text { Aggregate } \\
\text { efficiency }\end{array}$ \\
\hline 1 & -5.88 & -5.78 & -8.49 & -1.21 & -9.31 & 6.36 & 0.00 & -8.10 & 8.11 \\
\hline 5 & -6.02 & -8.82 & -9.34 & -0.29 & -10.08 & 4.91 & 2.93 & -8.95 & 10.73 \\
\hline 10 & -6.37 & -10.06 & -9.76 & 0.17 & -10.45 & 3.45 & 3.84 & -9.35 & 12.65 \\
\hline 20 & -7.05 & -10.48 & -9.96 & 0.40 & -10.61 & 2.74 & 3.48 & -9.58 & 15.87 \\
\hline 35 & -8.10 & -10.68 & -10.11 & 0.57 & -10.74 & 2.46 & 2.46 & -9.78 & 21.47 \\
\hline
\end{tabular}




\section{Figure 1: Elimination of all tariffs on European goods}

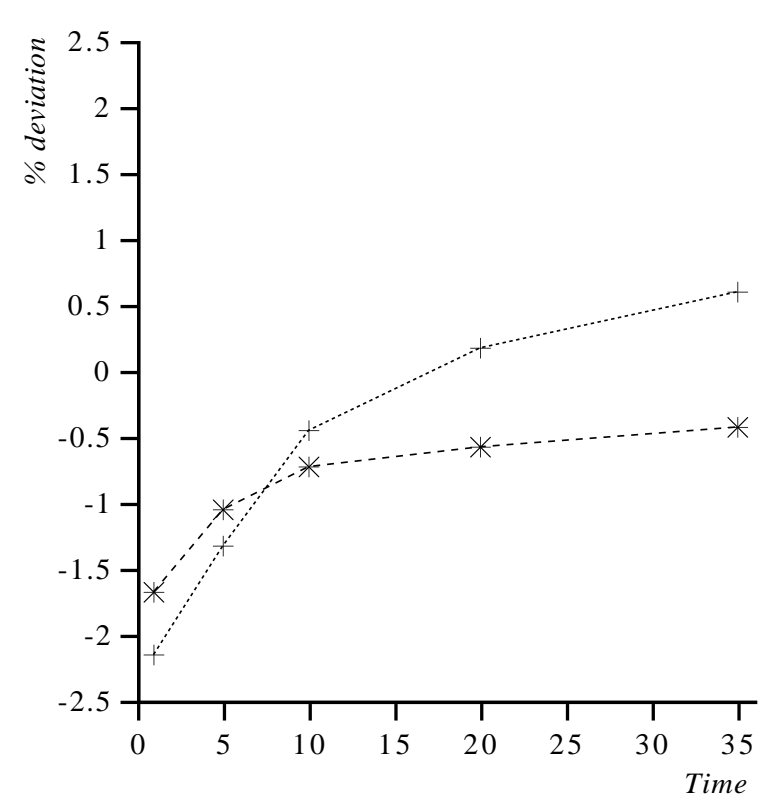

Consumption



Investment

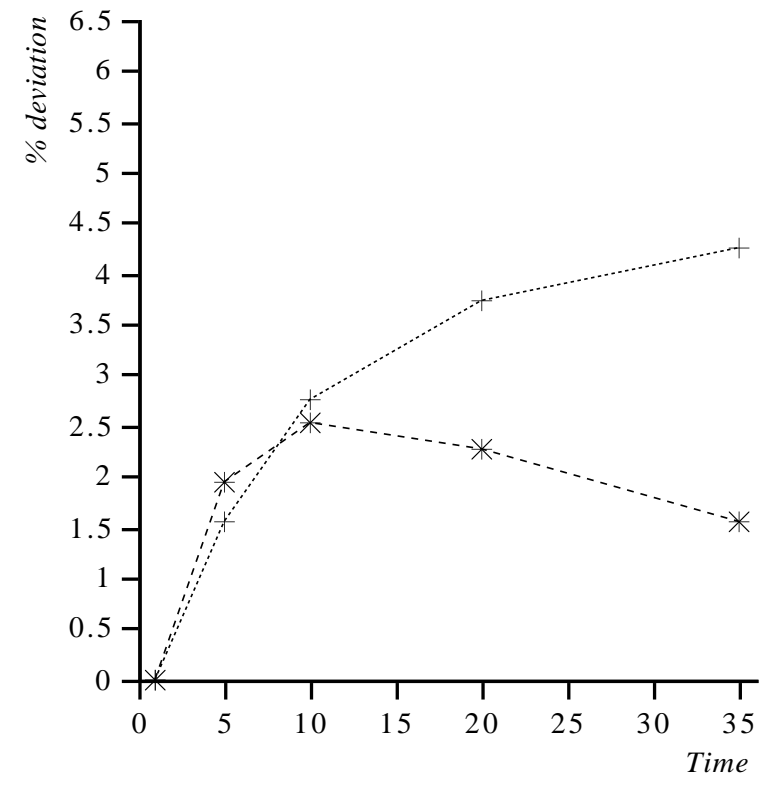

Capital 


\section{Figure 2: Full integration in the European Single Market}

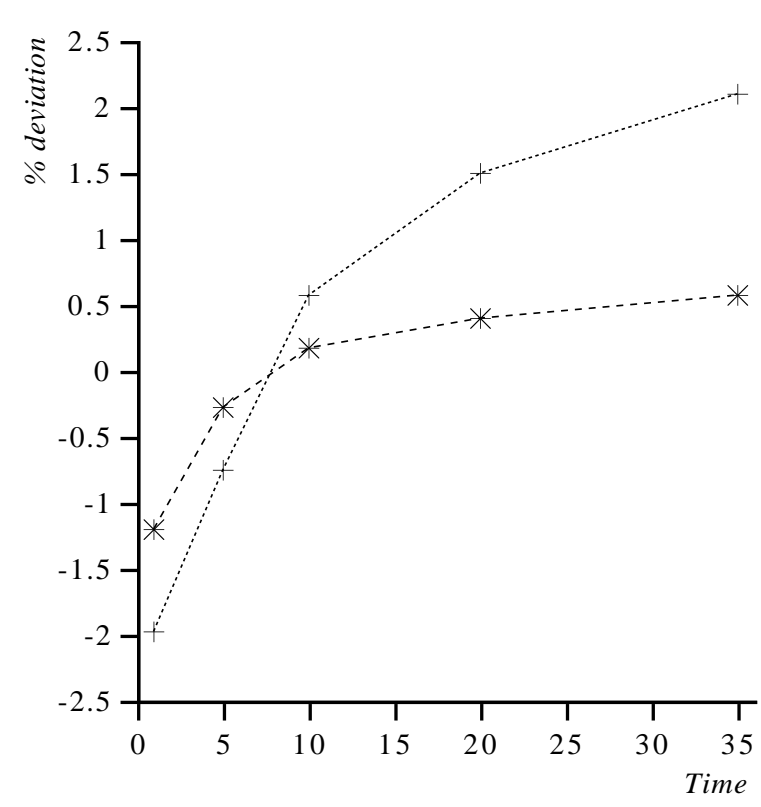

Consumption

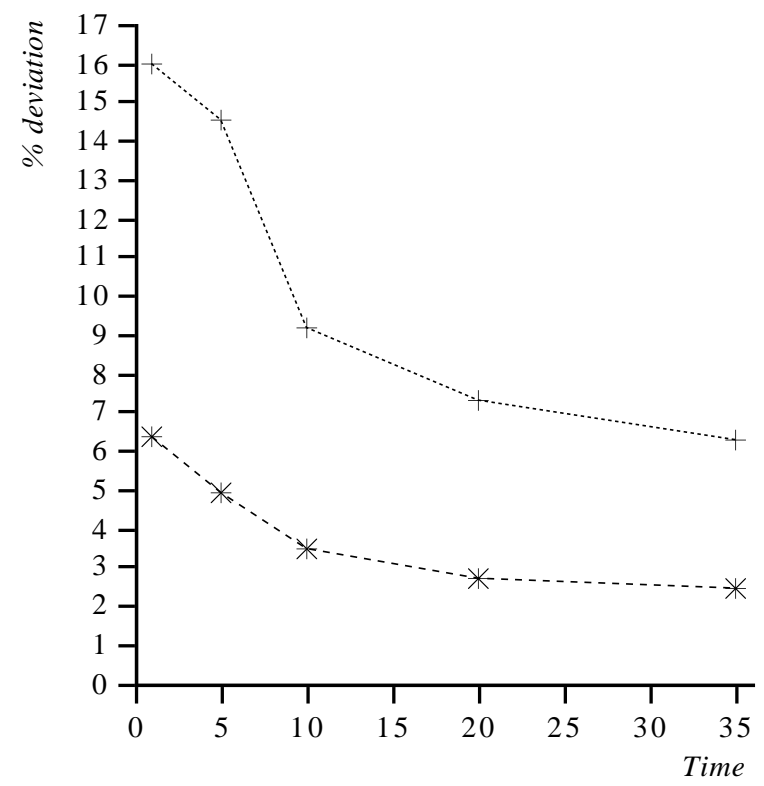

Investment

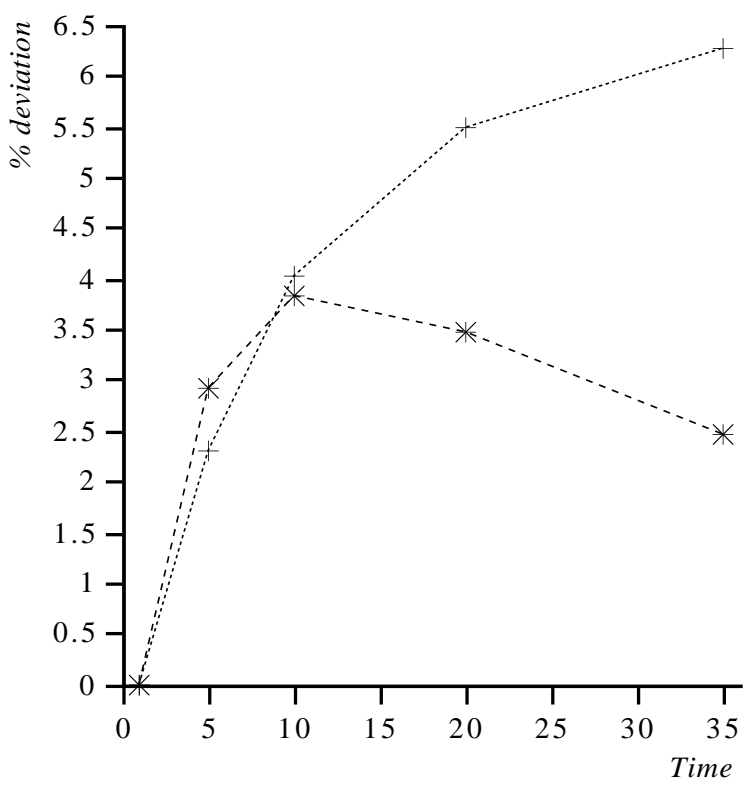

Capital 